\title{
The über-GP:
} an exploration of clinical excellence, leadership, and patient-centred care in general practice

\author{
Mayur Lakhani
}

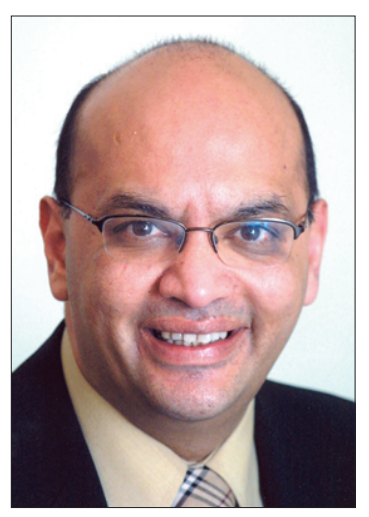

\section{CELEBRATING GENERAL PRACTICE}

On 20 December 1952, the British Medical Journal announced the foundation of a college of GPs, now the Royal College of General Practitioners (RCGP). ${ }^{1}$ The College had a strong vision for general practice. A singular achievement was vocational training. ${ }^{2}$ Sir James Mackenzie would have been proud of this, as he had himself advocated special training for GPs. There has been immense progress since then. We now have one of the finest systems of general practice in the world:

- 259 million consultations every year and rising;

- 1.5 million prescriptions issued every day;

- $90 \%$ of the work of the NHS done in primary care;

- impressive levels of patient satisfaction of $91 \%$;

- high levels of trust in GPs;

- a prized new specialist training and assessment system;

- research in primary care that is rated as world class; and

- over one-third of all practices involved in teaching medical students.

There are also examples of the professionalism of individual GPs up and down the country: the GP who has made that early diagnosis of meningitis in a baby and the GP who deals with the frail older patient with heart failure.

\section{Concerns about the future}

There is much to celebrate but we have more work to do. As a practising doctor, I want to do more for my patients. There is much more that we can, and need to do. Take some examples: Mrs Patel is 66, she is distressed, she is crying because she is dying from advanced bladder cancer; her GP failed to diagnose the cancer early enough. Mrs Jones is 86 and has complex multiple medical conditions; her health is declining. She has repeated hospital admissions and multiple referrals without any obvious medical benefit. Actually, she is dying and approaching the end of her life but this goes unrecognised in the health system. People are also concerned about the future of general practice. Take Natalie who is a medical student and who wants to be a GP. What shall we say to Natalie about the future? What kind of doctor will she need to be to succeed in serving patients?

\section{MACKENZIE'S GOLDEN THREAD}

The title of my lecture is 'The über-GP'. By über I mean super or the epitome. The stories I have told you exemplify the key issues that affect all of our futures. What is the epitome of a GP? I have taken inspiration from the life of Sir James Mackenzie. ${ }^{3}$ Three things strike me about Mackenzie. First, his meticulous clinical work and diagnoses. Secondly, the care and compassion he showed for his patients; Professor Sir John McMichael wrote that Mackenzie

M Lakhani, CBE, FRCGP, chair of the National Council for Palliative Care, Highgate Medical Centre, Loughborough.

This text is based on the James Mackenzie Lecture delivered at the Royal College of General Practitioners' Annual General Meeting, London, on 20 November 2009.

Address for correspondence

Professor Mayur Lakhani, Highgate Medical Centre, 5 Storer Close, Sileby, Loughborough LE12 7UD.

E-mail: MK.Lakhani@gp-c82644.nhs.uk

Submitted: 10 May 2010; Editor's response: 21 June 2010; final acceptance: 22 July 2010.

(C)British Journal of General Practice 2011; 61: 218-220.

DOI: 10.3399/bjgp11X561258 
has the 'practical wisdom of a good caring doctor'. Finally, his leadership - wherever he went, things happened - new organisations were formed and progress was made. Mackenzie was a visionary. This combination of clinical excellence, caring, and leadership runs through Mackenzie's career like a golden thread.

\section{CLINICAL GENERAL PRACTICE AND PERSONALISED MEDICINE}

The motto of our College is Cum Scientia Caritas, which means scientific knowledge applied with compassion. I want to advocate a stronger role for clinical medicine in general practice and emphasise the importance of diagnosis to meet the challenge of translational medicine. The Office of Science and Technology of the House of Commons released a report in April 2009 on personalised medicine. Personalised medicine means tailoring treatment to the individual profile of people, including DNA information. I predict that personalised medicine will become more widespread and it will move from the province of specialists to generalists, which will have implications for GPs. Take for example, the progress made in defeating cancer by understanding p53, the 'guardian angel gene'. ${ }^{5}$ am in no doubt that the new genetics will lead to the widespread clinical application of tailored medicines, vaccines, and diagnostic tools. Who better to make sure that patients benefit systematically and ethically from these developments than well-trained and skilled GPs with their registered lists?

Stronger clinical medicine will enhance the diagnostic function of GPs. In 2007, the RCGP launched its roadmap for the future direction of general practice, ${ }^{6}$ which sets out the role and function of a GP. As chairman I used to receive letters from members of the public about missed diagnoses, which is the commonest cause of successful litigation. ${ }^{7}$ This is something that also worries GPs very much.

When I meet members of the public, I sometimes like to ask people what they like about their GP. So when I met Neil, I asked him. He is a young, married man with two children. He replied: 'I really like to see Dr Mike at the practice - he is very good at diagnosis'. It is good for a doctor to be recognised for their diagnostic ability.

Our observations today in general practice could be tomorrow's vital discovery and breakthrough, just like the work of Mackenzie. We have to have that inquisitive and curious culture that promotes excellence. Let us have a comeback for clinical excellence and a culture that can allow GPs to innovate and make discoveries, and new ideas to flourish.

\section{THE PERSONAL DOCTOR}

A caring personal doctor is essential for delivery of good technical care. Science and caring are two sides of the same coin. Mackenzie said that clinical medicine should include 'the feelings of men and women'. The Picker Institute has identified the dimensions of patient-centred care. ${ }^{8}$ Research by Moira Stewart and her colleagues has shown that the patient-centred method improves a range of outcomes. ${ }^{9}$ Patient-centred medicine has the power to transform health care and to do this best, you need continuity of care. This is essential to deal with the fragmentation of care that patients suffer; fragmentation is the scourge of modern medicine. A retired senior doctor told me recently:

'I have great difficulty in getting good care for my mother who is 94 years old, we do not even know which GP is responsible for her in the practice, and getting home visits is well, nigh impossible.'

\section{NAMED PERSONAL DOCTOR}

In 2000 the College of Family Physicians of Canada issued a key document calling for every Canadian to have a named, personal family physician within a practice they call a medical home. ${ }^{10}$ While others are moving towards this model, I am concerned that we, in the home of general practice, are moving away from personal care. The NHS does not prioritise continuity of care and it must do.

We are at a critical juncture and face two choices: we can allow a relentless development of clinics, and centres where you see any doctor, or we can have a situation where we have general practice that encourages continuity of care. Continuity of care is within our control and certainly within our sphere of influence.

If we do not do this, then I am concerned that we will unwittingly become party to collusion of anonymity as described by Balint. ${ }^{11}$ Patients do not like repeating stories. They suffer disruption of care across interfaces, and harm can occur. ${ }^{12}$

Therefore, patients need, more than ever, what Balint called the 'conductor of the orchestra'. ${ }^{11}$ Bringing back personal care and named doctors would also improve quality and productivity, issues that are really concerning the health service in a cold economic climate. We have to create the opportunities to allow continuity of care not just in primary care but also in secondary care. The language of personal doctoring - my doctor, my patient - is powerful and evocative. It is the essence of medicine.

\section{THE ÜBER-GP}

The future is exciting for general practice. We already 
have outstanding examples of GP leadership, but now we need to accelerate change. We can learn from Mackenzie who was focused on excellence and caring and who made things happen. Such a powerful combination would be, in my view, the epitome of a doctor: the über-GP. This signifies the triple role of a GP: the clinically excellent doctor, the patient-centred doctor, and the doctor who strives for improvement through leadership. This new dynamic of the triple role, the über-GP should be our offer to the NHS as the product of specialist training.

\section{ÜBER-GPS ALREADY EXIST!}

The über-GP already exists! Doctors who are clinically excellent, who care for their patients, and who are leaders in their own chosen fields and interests are über-GPs. Thousands of GPs up and down the country are delivering good clinical care, being personal doctors and providing leadership, pursuing the triple role, and making the triple diagnosis. We may not believe it of course, because we are naturally reticent and tend to underplay our strengths. This is not about superheroes or exceptional or remarkable doctors. Excellence is within the reach of all of us. It is about the best of general practice everywhere. The history of general practice shows that we have generated solutions in the face of apparent crises and uncertainty. Critical to this endeavour will be better models of care and more support for GPs. We need to bring service and academia together, as this will help us achieve even better clinical outcomes. The ambitions set out by our founders will not be complete until we come to love, embrace, and respect research. Paraphrasing Sir William Osler, I say today let there be an invasion of primary care by universities so that we can have more clinical science in primary care. There are tremendous opportunities through the creation of institutions in primary care, such as federations and academic health science centres.

\section{THE FUTURE GP}

What then should we say to young people like Natalie, contemplating a career in general practice? I would say that it would be an excellent career choice. I really enjoy my work. I am looking forward to going into work next week. There has never been a better time to be a doctor. Look at all the epochmaking treatments we have, fantastic new diagnostic methods, and the support we get, for example, in palliative care.

So what would 'good' look like for Natalie's future? I see Natalie working in a university-supported federation (consortium) of practices. She will have her own list of patients and beds in the community hospital. She will be a personal doctor within a medical 'home'. She can call in consultants to consult but not to take over the patients. She will have support from a dedicated team of staff for coordination and integration of care. She will have responsive community pathology services, with results back in minutes. She will be able to spend 15 minutes with patients; she will have many tools for shared decision making and patients who have selfcare competencies to navigate choices. She has a clinical dashboard that tells her her benchmarked clinical outcomes in real time. She will be an ownerprincipal of the federation. She is able to choose the colour of the carpet in her room and the wall art that she wants to display!

It is distinctly possible to achieve professional happiness in general practice. To do this, I would say to her and everyone else here: be the best doctor that you can be, by following the über-values of clinical excellence, continuity of care, and leadership, just like Sir James Mackenzie.

\section{Acknowledgements}

I would like to thank my family and the many friends who have given me encouragement and support in my career to date, culminating in this lecture. I would also like to thank Claire Jackson, archivist at the RCGP.

\section{Discuss this article}

Contribute and read comments about this article on the Discussion Forum: http://www.rcgp.org.uk/bjgp-discuss

\section{REFERENCES}

1. Anonymous. A College of General Practitioners: Report of the General Practice Steering Committee (1952). Br Med J 1952; 2(4798): 1321-1328. doi:10.1136/bmj.2.4798.1321.

2. Lakhani M (ed). A celebration of general practice. Abingdon: Radcliffe Medical Press, 2003.

3. Mair A. Sir James Mackenzie MD 1853-1925 general practitioner. London: Royal College of General Practitioners, 1986.

4. Parliamentary Office of Science and Technology. Personalised medicine. Postnote April 2009; Number 329. http://www.parliament.uk/documents/post/postpn329.pdf (accessed 24 Jan 2011).

5. Koshland DE. The molecule of the year. Science 1993; 262(5142): 1993. DOI: $10.1126 /$ science.8266084.

6. Lakhani M, Baker M, Field $\mathrm{S}$. The future direction of general practice. A roadmap. London: Royal College of General Practitioners, 2007.

7. Royal College of General Practitioners. In safer hands. London: Royal College of General Practitioners, 2003.

8. Picker Institute. Principles of patient-centered care. http://pickerinstitute.org/about/picker-principles/ (accessed 27 Jan 2010).

9. Stewart M, Belle Brown J, Weston WW, et al. Patient-centred medicine. Transforming the clinical method. Abingdon: Radcliffe Medical Press, 2003.

10. The College of Family Physicians of Canada. Patient-centred primary care in Canada. Bring it on home. Discussion paper. http://www.cfpc.ca/uploadedFiles/Resources/Resource_Items/Bring2 0it20on20Home20FINAL20ENGLISH.pdf (accessed 24 Jan 2011).

11. Balint M. The doctor, his patient and the illness. London: Tavistock Publications, 1957.

12. Wilson T, Sheik A. Enhancing public safety in primary care. $B M J$ 2002; 324(7337): 584-587. 